\title{
Avaliação de métodos radiológicos na detecção de corpo estranho de madeira em modelo animal
}

\author{
Neil Grant Venter ${ }^{2}$, Nelson Jamel ${ }^{3}$, Ruy Garcia Marques ${ }^{4}$, Flavia Djahjah $^{5}$, Leonardo de Souza Mendonça ${ }^{6}$
}

Venter NG, Jamel N, Marques RG, Djahjah F, Mendonça LS. Avaliação de métodos radiológicos na detecção de corpo estranho de madeira em modelo animal. Acta Cir Bras [serial on line] Available from: URL: htt://www.scielo.br/acb

RESUMO - Avaliar diferentes métodos radiológicos no diagnóstico de corpos estranhos (CEs) de madeira. Métodos: Foram utilizados 11 frangos adultos. Realizou-se lesão perfurante, em cada sobrecoxa do animal. Em um dos lados, foi introduzida e deixada uma farpa de madeira e, na sobrecoxa contralateral, esse mesmo objeto foi introduzido e retirado (Grupo Controle). Após sete dias, os animais foram mortos e tiveram seus membros retirados para avaliação por radiografia simples (RS), ultra-sonografia (US), tomografia computadorizada (TC) e ressonância magnética (RM). Cada exame foi avaliado, independentemente, por dois radiologistas experientes. Resultados: A sensibilidade foi 13,6\% para RS, 63,3\% para US, 59,1\% para RMe 72,7\% para TC, com especificidades de $100 \%, 100 \%, 95,5 \%$ e $95,5 \%$, respectivamente. O valor preditivo positivo foi de $100 \%$ para RS e US, de $95 \%$ para TC e de $93,8 \%$ para RM, enquanto o valor preditivo negativo foi de $53,7 \%, 73,7 \%, 78,3 \%$ e 70,1\%, respectivamente. Aacurácia foi de $84,1 \%$, para TC, de 81,8\% para US, de 77,3\% para RM e de 56,8\% para RS. Comprovou-se, histologicamente, presença de reação inflamatória em todas as sobrecoxas que continham CE. Conclusão: RS apresenta pequena utilidade na detecção radiológica de CE de madeira em frango, devendo-se optar pelo emprego de US e TC, seguido por RM.

DESCRITORES: Corpo estranho; madeira; radiografia simples; ultra-sonografia; tomografia computadorizada; ressonância magnética.

\section{Introdução}

Durante toda a vida, estamos constantemente expostos a diversos riscos, que podem resultar em lesões. Sempre que ocorre rompimento da integridade da pele, existe a possibilidade de se instalar um corpo estranho (CE), podendo qualquer material agir como tal, não existindo local no corpo onde ele não possa se instalar. Podemos, assim, definir CE como qualquer material habitualmente não encontrado no organismo e que nele penetrou ou foi, acidental ou intencionalmente, introduzido, podendo desencadear graus diferentes de reação inflamatória. Ressalte-se que o termo CE não significa, necessariamente, algo deletério. Em Cirurgia, intencionalmente, estamos sempre utilizando corpos estranhos durante intervenções, como, por exemplo, fios para sutura, placas e fios ortopédicos, válvulas cardíacas, etc. Eventualmente, esses materiais estranhos ao organismo, muitos dos quais tidos como inertes, podem desencadear reação inflamatória, infecção ou migrarem para outros locais, dentre outros comportamentos deletérios, caracterizando-se, então, como "verdadeiros" corpos estranhos.

Um corpo estranho pode ser composto por qualquer material, sendo vidro e madeira os mais comumente encontrados ${ }^{1,2}$. Madeira e espinhos vegetais são radiotransparentes, prove- nientes de traumas de baixa intensidade e costumam se alojar próximo à superfície, podendo, contudo, penetrar nas cavidades torácica ou abdominal. Vidro é sempre radiopaco ${ }^{3,4}$, porém a sua transparência o torna de difícil visualização na ferida. Os objetos metálicos mais comuns são agulha e projétil de arma de fogo, que também são radiopacos e, comumente, inertes. Cada material provoca um tipo de reação inflamatória peculiar que, além de influenciada pela composição do material, sofre variações induzidas pela textura, localização e associação com infecção ${ }^{1,5}$.

Para auxiliar no diagnóstico de CE, são utilizadas radiografia simples convencional (RS), ultra-sonografia (US), tomografia computadorizada (TC) e ressonância magnética (RM). Esses exames podem mostrar sinais diretos - o próprio corpo estranho - ou sinais indiretos, que correspondem a edema, tecido de granulação e abscesso ${ }^{6,7}$. Esses sinais secundários aumentam a sensibilidade da propedêutica radiológica, fornecendo subsídios para a presunção da existência de $\mathrm{CE}(6)$.

É imperativo realizar o diagnóstico de CE que, além de danoso para o paciente, habitualmente necessita ser tratado através de intervenções cirúrgicas. Os diversos métodos radiológicos não representam, apenas, o papel de confirmação diagnóstica, evitando operações desnecessárias, mas tam-

1. Trabalho realizado no Curso de Pós-Graduação em Cirurgia (Área de Concentração: Abdome) - UFRJ, no Laboratório de Cirurgia Experimental da Faculdade de Ciências Médicas - UERJ e no Setor de Radiologia do Hospital Quinta D’Or - RJ.

2. Aluno de Mestrado em Cirurgia (Área de Concentração: Abdome) - UFRJ.

3. Professor Titular do Departamento de Cirurgia da Faculdade de Medicina - UFRJ.

4. Professor Adjunto do Departamento de Cirurgia Geral da Faculdade de Ciências Médicas - UERJ.

5. Aluna de Mestrado em Anatomia - UFRJ.

5. Aluno de Graduação em Biologia - UERJ. 
bém podem auxiliar na localização e retirada do $\mathrm{CE}$ e, com isso, diminuir tempo e dano causados pela intervenção .

O modelo experimental que idealizamos utiliza animais vivos, submetidos à introdução de CE de madeira, no intuito de se avaliar a fidedignidade diagnóstica dos quatro métodos radiológicos: RS, US, TC e RM.

\section{Métodos}

A parte cirúrgica deste trabalho foi realizada no Laboratório de Cirurgia Experimental da Faculdade de Ciências Médicas Universidade do Estado do Rio de Janeiro, e o estudo radiológico, no Setor de Radiologia do Hospital Quinta D'Or - Rio de Janeiro.

Utilizou-se um modelo experimental com frangos submetidos à introdução de corpo estranho de madeira, no tecido muscular da sobrecoxa. Foram avaliados quatro métodos radiológicos: radiografia simples, ultra-sonografia, tomografia computadorizada e ressonância magnética.

\section{Amostra}

Foram utilizados 11 frangos adultos (Gallus gallus), com aproximadamente 45 dias de vida, pesando, em média, 2900g. Cada animal participou, simultaneamente, dos dois grupos de estudo formados, pois em uma das sobrecoxas se procedeu à introdução e subseqüente retirada de corpo estranho de madeira (Grupo Controle) e, na sobrecoxa contralateral, foi introduzido e deixado um corpo estranho de madeira, com as mesmas características. Ambos os grupos, portanto, contêm 11 sobrecoxas de frango.

Os frangos foram provenientes de um abatedouro comercial e durante todo o período do experimento receberam ração apropriada (Natural FrangosÒ - PurinaÒ, Barra Mansa - RJ) e água ad libitum.

Os animais foram alojados em gaiolas apropriadas com, no máximo, quatro frangos por gaiola.

\section{Procedimento cirúrgico}

Após jejum de seis horas, os animais foram submetidos à anestesia intramuscular com cloridrato de cetamina (KetaminaÒ-Cristália ${ }^{\circledR}$, Itapira - SP), na dose de $40 \mathrm{mg} / \mathrm{kg}$ de peso, controlada pela freqüência cardíaca e pelo reflexo corneano. A seguir, foram colocados em decúbito dorsal e contidos na mesa operatória. Realizamos remoção das penas do local cirúrgico, anti-sepsia com polivinilpirrolidona (RiodeineÒ - RioquimicaÒ, São José do Rio Preto - SP) e colocação de campos operatórios fenestrados.

Os frangos sofreram uma lesão perfurante em uma das sobrecoxas, seguida por dissecção com pinça de Kelly e posterior introdução de um corpo estranho de madeira cilíndrico, com 1,5 cm de comprimento (palito de dente), sendo o mesmo processo realizado na sobrecoxa contralateral. Aleatoriamente, um dos corpos estranhos foi removido e o outro ficou retido, sendo marcada a sobrecoxa que o continha. As feridas de ambas as coxas foram fechadas com fio de náilon monofilamentar 4-0 (EthilonÒ - EthiconÒ, São José dos Campos - SP).

No pós-operatório imediato, os animais foram observados na mesa cirúrgica, até a recuperação de sua atividade física. Em seguida, foram recolocados em suas gaiolas, sem restrição alimentar, e passaram a ser acompanhados diariamente.

\section{Retirada do tecido para exame}

Após sete dias, os animais foram mortos, por deslocamento cervical, sob anestesia intramuscular com cloridrato de cetamina, e tiveram os membros operados removidos e depenados. A seguir, as peças foram levadas para realização dos exames radiológicos.

\section{Procedimentos radiológicos}

As coxas foram divididas em quatro grupos, permitindo que as diversas modalidades de exames radiológicos fossem realizadas, em cada grupo, simultaneamente. Após a realização do exame em um grupo, as coxas eram levadas para o local do próximo exame.

Cada modalidade radiológica foi avaliada por dois radiologistas experientes, individualmente e sem limite de tempo, não sendo permitido palpar as peças, para não influenciar no laudo. Aos radiologistas, foi solicitado analisar a presença de sinais diretos (o próprio $\mathrm{CE}$ ) e indiretos, bem como se o diagnóstico confirmava a presença do $\mathrm{CE}$.

\section{Equipamentos e técnicas utilizadas}

Todas as peças foram examinadas com a utilização dos seguintes equipamentos e técnicas: RS - aparelho VertixÒ (SiemensÒ, Alemanha), utilizando-se parâmetros para partes moles, com técnica e ecran digitais; US - aparelho HDI 5000Oे (ATL BothellÒ, EUA), com sonda multifreqüencial (5 a $12 \mathrm{MHz}$ ) e análise multiplanar; TC - aparelho de quarta geração, modelo Vision SecuraÒ (Phillips Medical SystemsÒ, Holanda) - as imagens foram obtidas com $120 \mathrm{kV}, 140 \mathrm{~mA}, 0,7 \mathrm{~s}, 2 \mathrm{~mm}$ de espessura de corte, intervalo de reconstrução de $1.5 \mathrm{~mm}$, pitch de 1, matriz de 512 x 512, field of view (FOV) de $245 \mathrm{~mm}$ foram, posteriormente, analisadas as estações digitais de trabalho (EDT), com liberdade de ajuste da janela e magnificação; RM aparelho de alto campo, modelo Gyroscan Intera PowerÒ (Phillips Medical SystemsÒ, Holanda), com as sequiências SE T1 (TR/TE: 505,3/18,0 ms, número de excitações (nex) de 3, com $3 \mathrm{~mm}$ de espessura de corte e $0,3 \mathrm{~mm}$ de espaçamento, com matriz de 512 x 512 e FOV de 170 mm) e GRE T2 (TR/TE: 377,6/ $13,8 \mathrm{~ms}$, nex de 3 , com $3 \mathrm{~mm}$ de espessura de corte e $0,3 \mathrm{~mm}$ de espaçamento, com matriz de 512 x 512 e FOV de $150 \mathrm{~mm}$ ), que 
foram, posteriormente, analisadas em EDT, com liberdade de ajuste dos parâmetros de exibição.

\section{Análise histológica}

Depois de realizados os exames radiológicos, as sobrecoxas dos frangos foram abertas, confirmando-se a presença dos CEs em todas as 11 peças em que eles haviam sido deixados. Em quatro desses animais, constatou-se que o CE havia migrado para o espaço subdérmico.

Ressecou-se, com ampla margem, o local em que se encontrava o CE. Similarmente, nas sobrecoxas-controle, procedeu-se à ressecção tecidual ampla, no local onde havia sido introduzido (e retirado) o $\mathrm{CE}$.

Os fragmentos de sobrecoxa foram colocados em frascos contendo solução de formalina tamponada a 10\%. Processou-se o tecido em soluções crescentes de álcool e xilol e, em seguida, foi incluído em blocos de parafina (Parafina para Histologia ${ }^{\circledR}$ Merck $^{\circledR}$, Rio de Janeiro - RJ) e cortado, com o auxílio de um micrótomo rotativo (Leica RM2025 ${ }^{\circledR}$, Leica Instruments ${ }^{\circledR}-$ China), em fatias de $5 \mathrm{~m}$ de espessura. As lâminas, preparadas a partir dessas fatias, foram submetidas à coloração de hematoxilina e eosina, e analisadas em microscópio óptico (Micro DiastarÒ - Reichert ${ }^{\circledR}, \mathrm{NY}$ - EUA). Os exames histopatológicos foram realizados por médico-veterinário patologista.

\section{Análise estatística}

Os dados dos laudos foram aplicados em uma tabela em planilha do Excel $^{\circledR}$, onde foram calculados sensibilidade, especificidade, valor preditivo positivo (VPP), valor preditivo negativo (VPN) e acurácia.

Foi também utilizado o pacote estatístico (SPSS $10.0^{\circledR}$ SPSS Inc. ${ }^{\circledR}$, Chicago - EUA), com realização do teste KappaCohen para verificação do grau de concordância entre os radiologistas e também o teste não-paramétrico de Wilcoxon, para avaliar se havia diferença estatística entre os vários tipos de exames. Os seis graus possíveis de concordância gerados pelo teste de Kappa-Cohen, a partir da pontuação atingida, são: sem concordância, concordância fraca, concordância sofrível, concordância moderada, concordância substancial e concordância quase perfeita.

\section{Aspectos éticos na pesquisa com animais}

Este projeto foi aprovado pelo Comitê de Ética em Pesquisa com Animais do Instituto de Biologia Roberto Alcântara Gomes - Universidade do Estado do Rio de Janeiro.

Todos os procedimentos seguiram, rigorosamente, a regulamentação existente sobre experimentação com animais.

\section{Resultados}

A figura 1 demonstra a imagem do CE de madeira, obtida com cada um dos métodos de imagem utilizados.
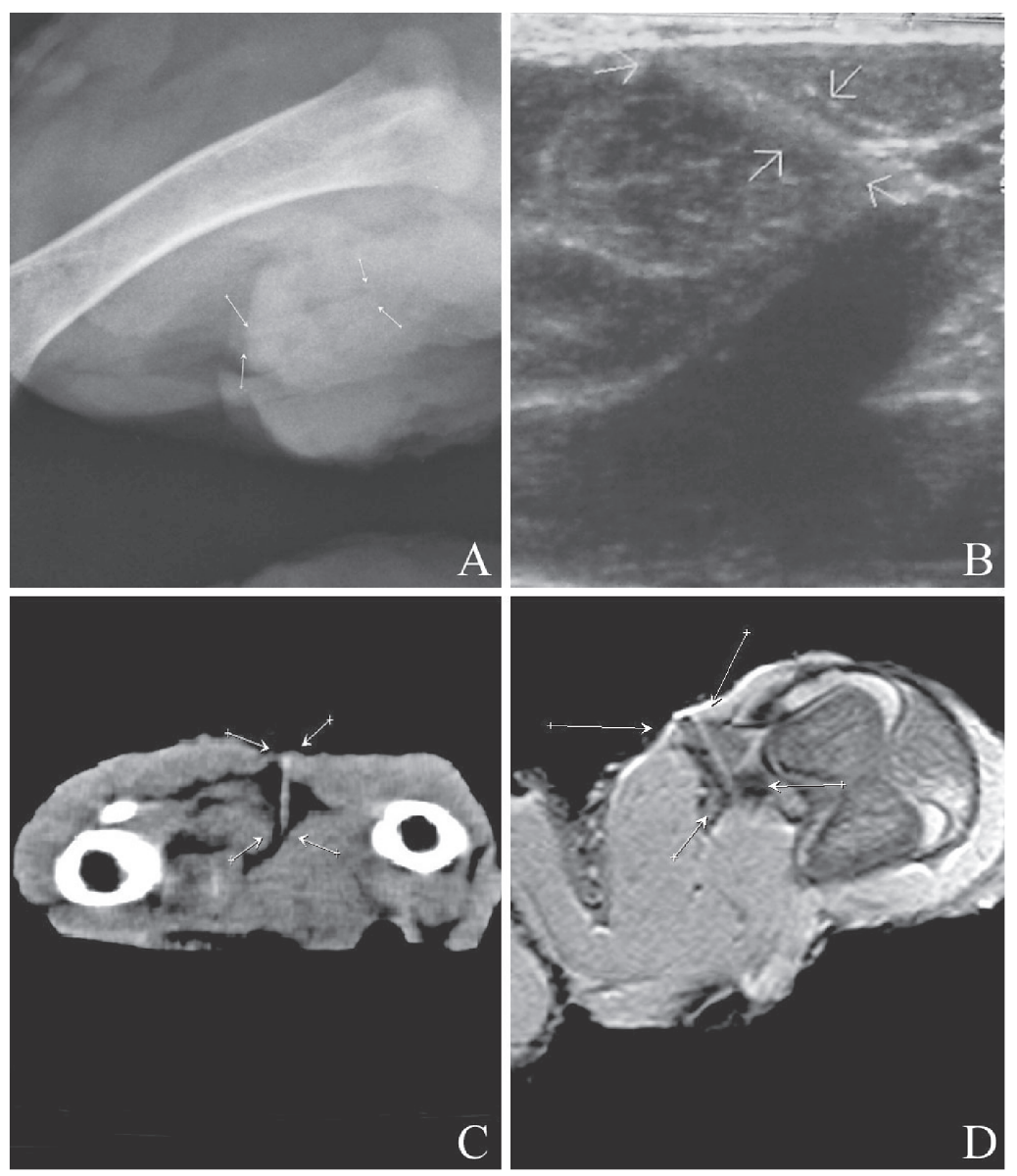

FIGURA 1 - Imagem obtida do corpo estranho de madeira, com cada um dos métodos radiológicos utilizados:

A - radiografia simples, demonstrando imagem linear discretamente hipotransparente (setas);

B - ultra-sonografia, demonstrando imagem linear hiperecóica (setas), com sombra acústica posterior;

C-tomografia computadorizada, demonstrando imagem linear hiperdensa (setas);

D - ressonância magnética, demonstrando imagem linear hipointensa (setas)

Acta Cirúrgica Brasileira - Vol 20 - Supl no 12005 - 21 
A tabela 1 mostra os valores percentuais obtidos para sensibilidade, especificidade, VPP, VPN e acurácia da radiografia simples, ultra-sonografia, tomografia computadorizada e ressonância magnética, na detecção do CE nas sobrecoxas de frango.

TABELA 1 - Comparação da sensibilidade, especificidade, VPP, VPN e acurácia entre as modalidades radiológicas empregadas.

\begin{tabular}{lcccc}
\hline & RS (\%) & US (\%) & RM (\%) & TC (\%) \\
\hline \hline Sensibilidade & 13,6 & 63,6 & 59,1 & 72,7 \\
Especificidade & 100 & 100 & 95,5 & 95,5 \\
VPP & 100 & 100 & 93,8 & 95 \\
VPN & 53,7 & 73,7 & 70,1 & 78,3 \\
Acurácia & 56,8 & 81,8 & 77,3 & 84,1 \\
\hline
\end{tabular}

VPP - valor preditivo positivo; VPN - valor preditivo negativo; RS - radiografia simples;

US - ultra-sonografia; RM - ressonância magnética; TC - tomografia computadorizada.

O valor de $\mathbf{K}$ foi significativamente alto para todos os exames realizados (tabela 2), não mostrando diferença estatística entre os examinadores.

TABELA 2 - Análise estatística com o teste Kappa-Cohen

\begin{tabular}{l|cc}
\hline & Kappa & p-valor \\
\hline \hline RS & 0,645 & 0,001 \\
US & 0,792 & 0,000 \\
RM & 0,584 & 0,005 \\
TC & 0,718 & 0,000 \\
\hline
\end{tabular}

RS - radiografia simples; US - ultra-sonografia; RM - ressonância magnética; TC - tomografia computadorizada

Os resultados do teste Kappa-Cohen interobservador foram considerados substanciais para RS, US e TC, e moderados para RM.

O resultado do teste de Wilcoxon (tabela 3) mostrou que existem diferenças estatisticamente significativas comparando-se
RS vs US ( $\mathrm{p}=0,034), \operatorname{RS} v s \mathrm{RM}(\mathrm{p}=0,08), \operatorname{RS} v s \mathrm{TC}(\mathrm{p}=0,005)$. As demais comparações entre métodos radiológicos, US vs RM, US vs TC e RM vs TC, não mostraram significância estatística.

TABELA3 - Análise estatística com o teste de Wilcoxon

\begin{tabular}{lcc}
\hline & $\mathrm{Z}$ & $\mathrm{p}$-valor \\
\hline \hline US - RS & $-2,121$ & 0,034 \\
RM - RS & $-2,646$ & 0,008 \\
TC - RS & $-2,828$ & 0,005 \\
RM - US & $-0,447$ & 0,655 \\
TC - US & $-1,000$ & 0,317 \\
TC - RM & $-0,577$ & 0,564 \\
\hline
\end{tabular}

RS - radiografia simples; US - ultra-sonografia; RM - ressonância magnética; TC - tomografia computadorizada

O exame histológico mostrou processo inflamatório crônico focal, de leve a moderado, constituído pela presença de leucócitos mononucleares e reação gigantocelular do tipo corpo estranho, sendo possível evidenciar, em algumas lâmi- nas, material de degeneração intracelular (Fig. 2). Foi ainda observada a presença de fibrose e de fragmentos do próprio $\mathrm{CE}$ de madeira, em alguns cortes histológicos. 


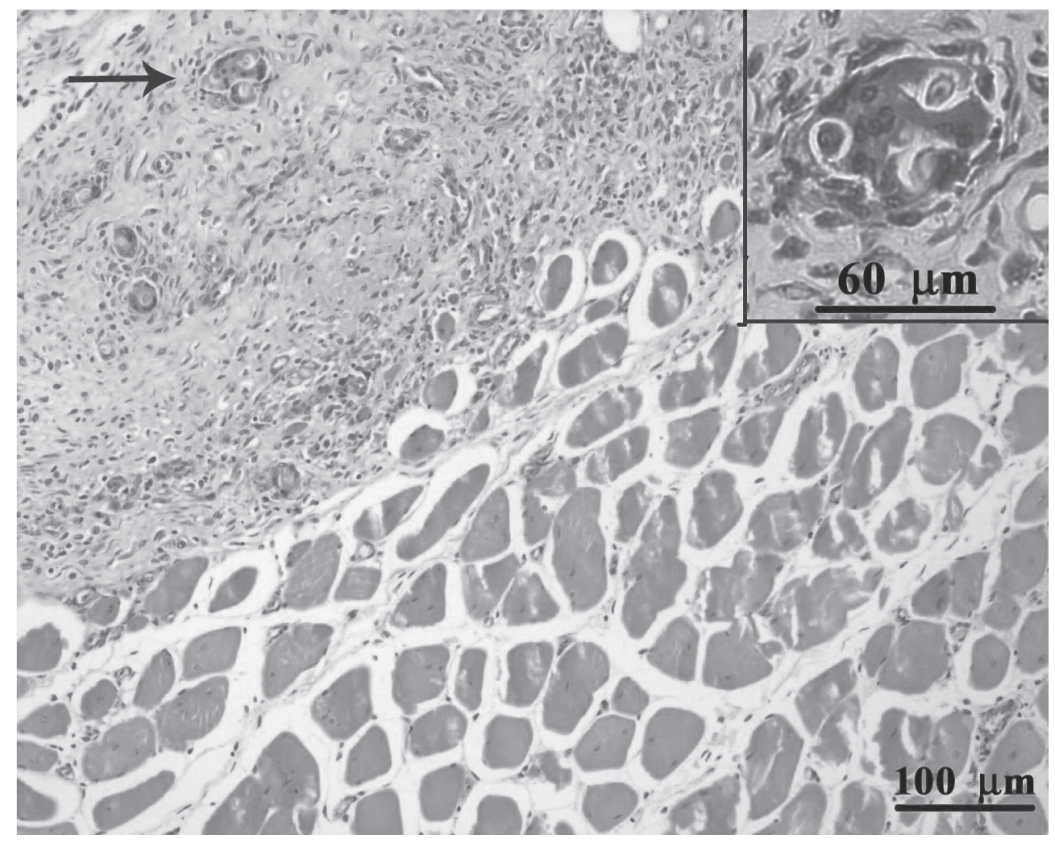

FIGURA 2 - Fotomicrografia de músculo esquelético de frango, exibindo área de fibrose com processo inflamatório crônico moderado e reação gigantocelular, com material de degradação. A seta mostra célula gigante com material de degradação (imagem ampliada em destaque). Coloração: hematoxilina e eosina. Barra $=100 \mathrm{~mm}$ (foto maior) $\mathrm{e}$ barra $=60 \mathrm{~mm}$ (destaque)

\section{Discussão}

A rotina do médico que atende um paciente com suspeita de CE pode ser muito prazerosa, quando se confirma o diagnóstico e se procede á sua remoção, ou, em contraposição, um desastre, causando angústia ao médico e pavor ao paciente. Estudos experimentais visando a avaliar a acurácia de diversas modalidades de exames radiológicos têm sido desenvolvidos desde 1932, quando Lewis avaliou a sensibilidade da RS em identificar pedaços de vidro (Apud Fordham, 1976) ${ }^{4}$.

Optamos pela utilização de madeira, pois esse material constitui um dos corpos estranhos mais comumente encontrados ${ }^{1,2}$, além de radiotransparente. Como modelo animal, utilizamos o frango, pelo fato de o seu membro se assemelhar anatomicamente à estrutura da mão humana, um dos locais de maior prevalência de CE.

O manejo do paciente com uma lesão que possa conter CE é complicado, pois a história do trauma pode não sugerir a sua presença e a exploração sistemática da ferida não garante a sua inexistência, necessitando, sobretudo, de profissionais treinados. O erro mais encontradiço no tratamento de um paciente com um CE retido é não diagnosticá-lo, uma vez que esses objetos se constituem em causas freqüentes de complicações, como infecção, disfunção motora e lesões neuromusculares, além de, não raramente, ensejar a abertura de processos judiciais contra o médico ${ }^{1}$.

O diagnóstico inicia-se com a história clínica, pois determinados tipos de lesão, como aquelas oriundas de colisões de veículos automotores, as perfurantes e as localizadas na cabeça têm maior probabilidade de conter um $\mathrm{CE}^{3}$. O paciente pode levar dias ou semanas antes de procurar atendimento médico, podendo até esquecer o mecanismo de trauma ou não lhe dar a devida importância, não o referindo ao médico atendente.
A sensação da presença do $\mathrm{CE}$ referida por alguns pacientes apresenta valor preditivo positivo (VPP) de $31 \%$ e valor preditivo negativo (VPN) de $89 \%$ (5). Os sinais clínicos mais habitualmente encontrados são: dor referida, tumoração palpável, dor à palpação profunda no local do $\mathrm{CE}$, infecções recorrentes ou resistentes, fístulas e retardo na cicatrização. Dor está presente em quase todos os pacientes e instiga atenção, principalmente, quando associada à massa palpável ${ }^{1}$. É importante lembrar que o CE pode estar presente, mesmo quando todos os exames radiológicos forem negativos, restando apenas a suspeita clínica para guiar a conduta médica, como, por exemplo, sói acontecer em pacientes com feridas com drenagem mantida e múltiplas culturas negativas.

Existem inúmeras publicações, tanto experimentais como relatos clínicos, com diferentes conclusões acerca da detecção de CEs. A maioria utilizou RS e US, pois são os exames mais antigos e mais disponíveis; outros utilizaram alguns métodos mais hodiernos, como TC e RM. Na literatura, apenas um estudo empregou todos os métodos utilizados neste trabalho, avaliando múltiplos materiais, como amálgama, fragmento de coroa dentária, asfalto e madeira, introduzidos em língua de boi(9). Muitas pesquisas relatam o emprego de blocos de carne, membros de frangos previamente abatidos ou cadáveres humanos, porém freqüentemente são alvos de sérias críticas: (1) constituem modelos que não apresentam múltiplos planos teciduais, como in vivo; e (2) não permitem a ocorrência de reação inflamatória, habitualmente induzida pelo CE. Neste estudo, visou-se a mimetizar a reação inflamatória, introduzindo o CE sete dias antes da avaliação e empregando as quatro modalidades radiológicas mais comumente disponíveis na maioria dos serviços de emergência.

A RS é um excelente método de triagem para detecção de CE, sendo necessárias apenas duas incidências, para a maioria dos segmentos corporais. Geralmente, essas incidências são pósteroanterior e perfil, com exceção de mão e pé, onde deve ser utilizada 
a incidência oblíqua, no lugar do perfil. A sensibilidade global da $\mathrm{RS}$, tanto para matérias radiopacas quanto radiotransparentes, situa-se acima de $80 \%$, chegando próximo a $100 \%$, somente para objetos radiopacos ${ }^{4}$. Considerando-se que todos os metais, à exceção do alumínio, são radiopacos, assim como o vidro, existem relatos em que a sensibilidade para detecção deste último material, com tamanho de $2 \mathrm{~mm}$, foi de $98,7 \%$ e, com $0,5 \mathrm{~mm}$, de $61,3 \%^{3}$. No caso de CE radiotransparente, como madeira, a sensibilidade varia de 0 a $15 \%{ }^{1,2,11}$.

Além de visualizar os sinais diretos, a RS nos permite observar também os indiretos, como aumento de partes moles, presença de gás e lesões ósseas do tipo osteoblástica, osteoclástica ou mistas $^{12}$. Outro emprego bastante útil é para a localização do CE com o auxílio de guias (agulhas introduzidas na pele, com tomadas radiográficas em várias incidências), para se triangular o local de incisão com boa fidedignidade. Mais modernamente, contudo, tem-se utilizado a radioscopia, que permite radiografias em tempo real, com a imagem demonstrada em uma tela, possibilitando guiar o instrumental cirúrgico até o CE. No nosso estudo, os CEs foram observados como imagens lineares discretamente hipotransparente (Figura 1A), e a sensibilidade da RS foi de apenas 13,6\%, com especificidade de $100 \%$, denotando o seu pequeno papel como método propedêutico para a detecção de CE de madeira.

A US permite visualizar todos os tipos de CEs, inclusive os radiotransparentes, informando, ainda, sua relação anatômica ${ }^{6,7}$. Qualquer CE apresenta-se como uma imagem hiperecóica, com ou sem sinais indiretos, representados por um halo hipoecóico e/ou sombra acústica. A presença de um dos dois sinais indiretos aumenta a sensibilidade do exame para detecção do $\mathrm{CE}^{6,8}$. A despeito de ser um exame barato, possui limitações, como ser operador-dependente e apresentar resultados falso-positivos para cicatrizes, ossos sesamóides e calcificações ${ }^{2,8}$.

Na literatura, alguns estudos sugerem que a US seja o melhor método para diagnosticar $\mathrm{CE}^{6,13}$. Com utilização de cadáveres, CEs de madeira, plástico, metal e vidro foram avaliados, indistintamente, e a sensibilidade e a especificidade variaram de $89 \%$ a $94 \%$ e de $94 \%$ a $99 \%{ }^{14,15}$, respectivamente. Quando foi utilizada somente a madeira, a sensibilidade e a especificidade foram de $93,3 \%$ e $96,7 \%$ para fragmentos medindo $0,5 \mathrm{~cm}$, e de $86,7 \%$ e $96,7 \%$ para fragmentos medindo $0,25 \mathrm{~cm}$, respectivamente ${ }^{8}$. Contudo, existem resultados bastante divergentes dos anteriores, como em uma pesquisa com sobrecoxas de frangos abatidos, em que a sensibilidade para madeira foi de apenas $50 \%{ }^{11}$.

Inúmeras séries clinicas comprovam o valor da US na detecção de CEs, com sensibilidade, especificidade, VPP, VPN e acurácia de $95,4 \%, 89,2 \%, 87,5 \%, 96,2 \%$ e $92 \%$, respectivamente ${ }^{2,7}$. Além de esse exame poder demonstrar a não-ocorrência de CEs, pode comprovar enfermidades completamente distintas da que se almejava diagnosticar, tais como abscessos.

A confiabilidade da US, quando utilizada por médicos clínicos de serviços de emergência (médicos não-radiologistas), comparado com radiologistas, também foi alvo de apreciação em dois estudos. No primeiro, avaliando sobrecoxas de frangos abatidos com CE de madeira (palito de dente), a sensibilidade alcançada para médicos não-radiologistas e radiologistas foi, respectivamente, de $80 \%$ vs $83 \%{ }^{16}$; no segundo, somente com médicos não-radiologistas, utilizando-se CEs de madeira e de plástico, em coxas humanas recém-amputadas, a sensibilidade atingiu $93 \%{ }^{17}$. Esses relatos comprovam que um médico não-radiologista, em serviços de emergência, pode diagnosticar, com segurança, a presença de um CE, constituindo esta a recomendação atual do American College of Emergency Physicians, nos Estados Unidos da América ${ }^{18}$.

No nosso estudo, os objetos de madeira se mostraram como uma imagem linear hiperecóica á US, com sombra acústica posterior (Figura 1B), sensibilidade de 63,6\%, especificidade de $100 \%$ e acurácia de $81,8 \%$, comportando-se como bons resultados na detecção do $\mathrm{CE}$. Entretanto, o fato de quatro dos objetos de madeira terem migrado para o espaço subdérmico, migração esta que faz parte da história natural de corpos estranhos retidos, acabou por levá-los a um local próximo demais à superfície, impedindo o perfeito foco da US, acarretando a diminuição de sua eficácia.

A TC, além de visualizar o próprio CE, pode demonstrar áreas de atenuação bem definidas. Na fase aguda, a madeira pode ser confundida com gás ${ }^{19}$, e sua imagem mudar com o tempo em que permanece no corpo, pois com a absorção de líquido, seu valor de atenuação aumenta ${ }^{20,23}$. A desvantagem é o fato de ser um exame caro e pouco disponível e, ao contrário da US, utilizar radiação ionizante.

Estudos experimentais mostram que objetos de madeira, na maioria dos casos, podem ser identificados pela $\mathrm{TC}^{9,19}$. Em humanos, podemos observar casos onde essa modalidade de exame evidenciou o CE, enquanto outras falharam ${ }^{20,22}$, e casos onde a TC prestou-se apenas para complementar o diagnóstico(20, 22). Em um relato com 39 pacientes, a TC sugeriu a presença de $14 \mathrm{CEs}$, enquanto a exploração cirúrgica revelou $20 \mathrm{CEs}$, resultando em uma sensibilidade de $70 \%$. Contudo, neste mesmo estudo, a US foi superior, com uma sensibilidade de $90 \%{ }^{13}$. Em nossa pesquisa, a madeira se apresentou como uma imagem hiperdensa à TC (Figura 1C) e, dentre todas as modalidades de exame, este apresentou os mais altos percentuais de sensibilidade e acurácia.

$\mathrm{Na} \mathrm{RM}$, a madeira apresenta-se como baixo sinal (hipointensa) nas fases $\mathrm{T} 1$ e $\mathrm{T} 2{ }^{12}$ ou como ausência de sinal, sendo esta possibilidade a de menor freqüência, podendo apresentar captação periférica de gadolínio - contraste mais utilizado em $\mathrm{RM}(24)$. Também podem-se visualizar sinais indiretos do CE, devido à inflamação adjacente ${ }^{21}$. Esse é, entretanto, um exame de alto custo e baixa disponibilidade.

Existem poucos estudos experimentais utilizando RM para detecção de CE, mas, ao menos no que se refere a objetos de madeira, este exame parece apresentar sensibilidade próxima a $100 \%$. Entretanto, esses estudos utilizaram modelos com apenas 
um plano tecidual ${ }^{9}$ ou CEs de maior tamanho do que os comumente encontrados na rotina clínica ${ }^{19}$. Deve-se ressaltar a relativa ineficiência da RM, quando comparada à TC e à US, ao se avaliarem CEs compostos por outros materiais, notadamente aqueles com propriedades ferromagnéticas, em que o campo magnético gerado por esse método radiológico induz à formação de artefatos, dificultando, sobremaneira, a interpretação do exame ${ }^{9,19}$. Na literatura também existem relatos de casos de pacientes com CEs retidos, submetidos a outras modalidades de exames, como RS ${ }^{12}$ e $\mathrm{TC}^{23}$, ambos inconclusivos, em que apenas a RM foi capaz de detectálos, ou foi utilizada como método complementar ${ }^{22,24}$. Esses fatos tornam a RM uma ferramenta útil para diagnosticar CE, porém não de escolha inicial. No nosso estudo, a RM observou o CE como uma imagem linear hipointensa (Figura 1D), mas com resultados inferiores aos obtidos com US e TC.

Mesmo com a introdução do CE em animal vivo e com período de permanência de sete dias, não evidenciamos sinais indiretos de sua presença, em nenhuma das modalidades de exames radiológicos utilizadas. Apesar da comprovação histológica de reação inflamatória, esta foi, no máximo, moderada, podendo ser diminuta demais para a capacidade de captação radiológica atual. Outra possível explicação para esse fato é o tempo decorrido entre a morte dos animais e o início dos exames, que, embora mínimo (duas horas), pode ter sido suficiente para tornar radiologicamente imperceptíveis quaisquer alterações porventura existentes.

Apesar dos nossos dados terem sido obtidos em frangos, analisando-os e aliando-os ao custo, disponibilidade e riscos oferecidos pelos métodos radiológicos habitualmente disponíveis, um algoritmo para identificação de CE de madeira pode ser indicado, a partir desse estudo. Nos casos de suspeita de CE de madeira, deve-se iniciar com a realização de US, pois, além de barato, este exame não apresenta radiação; não visualizando o $\mathrm{CE}$ e permanecendo a dúvida, deve ser realizada a TC; e, por último, deve-se empregar a RM. Inicialmente, não estaria indicada a RS, haja vista a sua baixa sensibilidade. Contudo, se o CE for composto, sabidamente, por um material radiopaco ou se não tivermos como precisar que tipo de material está presente, ou mesmo se existe a presença de algum CE, o algoritmo deverá se iniciar pela RS, pois esse exame apresenta boa sensibilidade global e disponibilidade, além do baixo custo. Deve-se lembrar que pode ser necessária a realização dos quatro exames para diagnosticar a presença de um CE, pois embora, eventualmente, o CE somente seja visualizado com RM, é mais provável que métodos mais disponíveis, como US e TC, sejam suficientes para o diagnóstico.

Uma das maiores dificuldades dos estudos experimentais refere-se à transposição de seus resultados para aplicação em seres humanos. Isto deve ser feito de maneira cautelosa, sem conclusões precipitadas, pois quaisquer resultados obtidos constituem verdades absolutas apenas para a espécie animal estudada. Levando-se em consideração a inexistência de estudos clínicos que comparem esses métodos radiológicos na avaliação diagnostica de CE e, especialmente, o fato de se constituírem na propedêutica radiológica não-invasiva habitualmente utilizada, a aplicação desse mesmo algoritmo pode encontrar justificativa para utilização clínica, sem quaisquer riscos aos pacientes. Estudos adicionais são necessários em outros modelos animais, submetidos aos mesmos exames e, preferencialmente, mantidos vivos, sob sedação, no intuito de se eliminar possíveis erros de interpretação.

\section{Conclusão}

No modelo animal utilizado, TC e US parecem apresentar a mesma eficácia na identificação de CE de madeira, com discreta vantagem para a TC, seguida pela RM. A RS parece não apresentar utilidade para o diagnóstico de CE de madeira.

\section{Referências}

1. Anderson MA, Newmeyer WL, 3rd, Kilgore ES, Jr. Diagnosis and treatment of retained foreign bodies in the hand. Am J Surg 1982;144:63-7.

2. Crawford R, Matheson AB. Clinical value of ultrasonography in the detection and removal of radiolucent foreign bodies. Injury 1989;20:341-3.

3. Courter BJ. Radiographic screening for glass foreign bodieswhat does a "negative" foreign body series really mean? Ann Emerg Med 1990;19:997-1000.

4. Fordham SD. The detection of glass foreign bodies. South Med J 1976;69:1484-5.

5. Steele MT, Tran LV, Watson WA, Muelleman RL. Retained glass foreign bodies in wounds: predictive value of wound characteristics, patient perception, and wound exploration. Am J Emerg Med 1998;16:627-30.

6. Boyse TD, Fessell DP, Jacobson JA, Lin J, van Holsbeeck MT, Hayes CW. US of soft-tissue foreign bodies and associated complications with surgical correlation. Radiographics 2001;21:1251-6.

7. Gilbert FJ, Campbell RS, Bayliss AP. The role of ultrasound in the detection of non-radiopaque foreign bodies. Clin Radiol 1990;41:109-12.

8. Jacobson JA, Powell A, Craig JG, Bouffard JA, van Holsbeeck MT. Wooden foreign bodies in soft tissue: detection at US. Radiology 1998;206:45-8.

9. Oikarinen KS, Nieminen TM, Makarainen H, Pyhtinen J. Visibility of foreign bodies in soft tissue in plain radiographs, computed tomography, magnetic resonance imaging, and ultrasound. An in vitro study. Int J Oral Maxillofac Surg 1993;22:119-24.

10. Donaldson JS. Radiographic imaging of foreign bodies in the hand. Hand Clin 1991;7:125-34.

11. Manthey DE, Storrow AB, Milbourn JM, Wagner BJ. Ultrasound versus radiography in the detection of soft-tissue foreign bodies. Ann Emerg Med 1996;28:7-9.

12. Laor T, Barnewolt CE. Nonradiopaque penetrating foreign body: “a sticky situation”. Pediatr Radiol 1999;29:702-4. 
13. Al-Zahrani S, Kremli M, Saadeddin M, Ikram A, Takroni T, Zeidan H. Ultrasonography Detection of Radiolucent Foreign Bodies in Soft Tissue Compared to Computed Tomography Scan. Ann Saudi Med 1995;15(2).

14. Bray PW, Mahoney JL, Campbell JP. Sensitivity and specificity of ultrasound in the diagnosis of foreign bodies in the hand. Am J Hand Surg 1995;20:661-6.

15. Blyme PJ, Lind T, Schantz K, Lavard P. Ultrasonographic detection of foreign bodies in soft tissue. A human cadaver study. Arch Orthop Trauma Surg 1990;110:24-5.

16. Orlinsky M, Knittel P, Feit T, Chan L, Mandavia D. The comparative accuracy of radiolucent foreign body detection using ultrasonography. Am J Emerg Med 2000;18:401-3.

17. Hill R, Conron R, Greissinger P, Heller M. Ultrasound for the detection of foreign bodies in human tissue. Ann Emerg Med 1997;29:353-6.

18. American College of Emergency Physicians. ACEP emergency ultrasound guidelines-2001. Ann Emerg Med 2001;38:470-81.
19. Russell RC, Williamson DA, Sullivan JW, Suchy H, Suliman O. Detection of foreign bodies in the hand. Am J Hand Surg 1991;16:2-11.

20. Yang I, Hayes CE, Jacobson JE, Jamadar DE, Wang S. Unique foreign body injury: bamboo penetration of thigh and pelvis while skiing. Emerg Radiol 2002;9:243-6.

21. Peterson JJ, Bancroft LW, Kransdorf MJ. Wooden foreign bodies: imaging appearance. Am J Roentgenol 2002;178:557-62.

22. Bodne D, Quinn SF, Cochran CF. Imaging foreign glass and wooden bodies of the extremities with CT and MR. J Comput Assist Tomogr 1988;12:608-11.

23. Imokawa H, Tazawa T, Sugiura N, Oyake D, Yosino K. Penetrating neck injuries involving wooden foreign bodies: the role of MRI and the misinterpretation of CT images. Auris Nasus Larynx 2003;30 Suppl:S145-7.

24. Kornreich L, Katz K, Horev G, Zeharia A, Mukamel M. Preoperative localization of a foreign body by magnetic resonance imaging. Eur J Radiol 1998;26:309-11.

Venter NG, Jamel N, Marques RG, Djahjah F, Mendonça LS. Evaluation of radiological methods for detection of wood foreign body in animal model. Acta Cir Bras [serial on line] Available from: URL: htt://www.scielo.br/acb.

ABSTRACT - Purpose: To determine the usefulness of different radiological methods in the diagnoses of wooden foreign bodies (FB). Methods: Eleven adult chickens were used. Each thigh received a puncture wound and in one of them a wooden splinter was introduced and left in place while in the contralateral it was introduced and removed (control group). After 7 days the animals where killed and the legs removed to be analyzed with conventional radiography (CR), ultrasonography (US), magnetic resonance and computed tomography. The results were viewed by 2 independent senior radiologists. Results: Sensitivity was: CR - 13.6\%; US $63.6 \%$; MR $-59.1 \%$; and CT $-72.7 \%$, with specificity of $100 \%, 100 \%, 95.5 \%$, and $95.5 \%$, respectively. The positive predictive value for CR and US was $100 \%, 95 \%$ for CT $95 \%$ and $93.8 \%$ for MR. CT had a negative predictive value of $78.3 \%$, while US, MR, and CR had $73.7 \%, 70.1 \%$, and $53.7 \%$, respectively. The accuracy for CT was $84.1 \%$, followed by US $-81.8 \%$, RM $-77.3 \%$, and CR $-56.8 \%$. Inflammatory reaction was histologically demonstrated in all thighs containing FB.Conclusion: CR showed a poor performance to detect wooden FB in chickens, while US and CT seem to be the best option, followed by RM.

KEYWORDS - Foreign body; radiography; ultrasonography; magnetic resonance; computed tomography

Correspondência:

Neil Grant Venter

Rua Ituverava, 702/403 - Freguesia - Jacarepaguá

22750-006 - Rio de Janeiro - RJ

neilventer@terra.com.br

Conflito de interesse - nenhum

Fonte de financiamento - nenhuma 